\title{
Stability and residual stresses of sputtered wurtzite AIScN thin films
}

\author{
Elmeri Österlund $\odot,{ }^{*}$ Glenn Ross $\odot$, Miguel A. Caro, and Mervi Paulasto-Kröckel \\ Aalto University, Department of Electrical Engineering and Automation, PO Box 13500, 00076 Aalto, Finland \\ Andreas Hollmann, Manuela Klaus, Matthias Meixner, and Christoph Genzel \\ Helmholtz-Zentrum Berlin für Materialien und Energie GmbH, Abteilung Mikrostruktur- und Spannungsanalyse, \\ Albert-Einstein-Straße 15, D-12489 Berlin, Germany \\ Panu Koppinen ${ }^{\dagger}$ and Tuomas Pensala $\odot$ \\ VTT Technical Research Center of Finland, 02150 Espoo, Finland \\ Agnè Žukauskaite $₫$ \\ Fraunhofer Institute for Applied Solid State Physics IAF, Tullastraße 72, D-79108 Freiburg, Germany \\ Michal Trebala \\ Aalto University, Department of Chemistry and Materials Science, PO Box 16100, 00076 Aalto, Finland
}

(Received 5 May 2020; accepted 19 January 2021; published 2 March 2021)

\begin{abstract}
Scandium-alloying of aluminum nitride $(\mathrm{AlScN})$ enhances the piezoelectric properties of the material and increases the performance of piezoelectric microelectromechanical systems (MEMS). However, this enhancement is caused by the destabilization of the wurtzite phase and so far the stability of AlScN thin films has not been sufficiently studied. Stability is especially important for piezoelectric devices because changes to the film microstructure or residual stress can lead to drastic changes in the device behavior. The stability of $\mathrm{AlScN}$ is investigated by annealing sputtered films and characterizing the resulting changes. It is found that the wurtzite phase of $\mathrm{Al}_{0.7} \mathrm{Sc}_{0.3} \mathrm{~N}$ is stable at least up to $100{ }^{\circ} \mathrm{C}$ and annealing increases the crystal quality, reaching a maximum at $800^{\circ} \mathrm{C}$. When annealed for more than $100 \mathrm{~h}$ at $1000^{\circ} \mathrm{C}$, argon used in sputtering segregates into the grain boundaries and causes compressive strains and formation of rock-salt phase. Additionally, annealing at $1000^{\circ} \mathrm{C}$ for $5 \mathrm{~h}$ reduces the average tensile stress by approximately $1 \mathrm{GPa}$.
\end{abstract}

DOI: 10.1103/PhysRevMaterials.5.035001

\section{INTRODUCTION}

Since the discovery of the anomalous piezoelectric effect in scandium-alloyed aluminum nitride (AlScN) in 2009 [1] there has been significant interest in wurtzite $\mathrm{Al}_{1-x} \mathrm{Sc}_{x} \mathrm{~N}$ thin films with (0002) texture for piezoelectric microelectromechanical systems (MEMS). The increase of the piezoelectric coefficients has been confirmed to be an intrinsic alloying effect caused by competing wurtzite and rock-salt phases, and due to the softening of the lattice [2-4]. The up to 500\% increase of the piezoelectric coefficients of AlScN compared to AlN can improve the performance of many MEMS devices, such as energy harvesters [3,5] and sensors, including piezoelectric micromachined ultrasound transducers (pMUT) [6].

\footnotetext{
*elmeri.osterlund@aalto.fi

${ }^{\dagger}$ Present address: Kyocera Tikitin Ltd., Tietotie 3, 02150 Espoo, Finland.
}

Published by the American Physical Society under the terms of the Creative Commons Attribution 4.0 International license. Further distribution of this work must maintain attribution to the author(s) and the published article's title, journal citation, and DOI.
AlScN thin films can be used in different types of RF filters as well [7]. Previous research on AlScN focused on increasing the piezoelectric properties with respect to Sc-content $[1,5,8-$ $10]$ and the reported optimal Sc-fraction $x$ varies from $27 \%$ to $43 \%$.

However, the previous studies did not assess the stability of AlScN thin films and mostly studied the as-deposited films or used only short annealing times [11] or low temperatures [1]. For a piezoelectric film, stability is especially important because even small changes in the film microstructure can affect the piezoelectric properties. Moreover, it is not accurately known at which Sc-concentration the phase change from wurtzite to rock-salt occurs and when a twophase mixture is possible. Density functional theory (DFT) studies suggest that the phase change occurs at an Scfraction of 56\%-64\% [4,8,12]. However, experimental studies with sputter-deposited films seem to indicate that the phase change occurs around $40 \%$ if the growth temperature is high $\left(400-580^{\circ} \mathrm{C}\right)[1,13]$ or around $30 \%$ if the temperature is low $\left(300^{\circ} \mathrm{C}\right)[10,14]$. Moreover, if AlScN is sputtered on a latticematched material, such as AlN or $\mathrm{ScN}$ leading to low epitaxial strain, mixtures of the two phases were observed at fractions between $10 \%$ and $50 \%[12,15]$. Whereas when $\mathrm{AlScN}$ is 
sputtered on $\mathrm{Si}$ or $\mathrm{Al}_{2} \mathrm{O}_{3}$ with larger lattice mismatch, the twophase pseudobinary mixture range is narrow or not observed at all. In short, high growth temperatures and tensile strains seem to increase the allowed Sc-content in as-deposited films, whereas compressive strain seems to at least reduce the crystal quality [16].

The observed mixtures of the wurtzite and rock-salt phase could be due to spinodal decomposition, which was observed both experimentally and theoretically $[8,12,17]$. Spinodal decomposition leads to local Al- and Sc-rich areas of wurtzite $\mathrm{AlScN}$ and the Sc-rich areas could then change into rock-salt, once it is energetically favorable to do so. Thermodynamic simulations show that epitaxial tensile strain increases the allowed Sc-fraction before spinodal decomposition occurs [8], which would explain the difference in the experimental results when $\mathrm{AlScN}$ is sputtered on different materials. The stabilizing effect of tensile strain has also been observed experimentally [16].

To ensure the reliability of $\mathrm{AlScN}$ thin films, it is important to study the stability of the microstructure, mechanical properties, and piezoelectric response. Moreover, strain relaxation might change the microstructure through spinodal decomposition [8]. Generally, understanding the residual stresses of thin films is important as they affect the reliability and operation of devices. Furthermore, understanding how stresses evolve is required because device behavior can change as a result. For example, the resonance frequency of pMUT devices depends on the residual stress of the film [18]. Residual stresses might affect the piezoelectric constants as well [19].

This study investigates the stability of AlScN thin films by annealing sputter-deposited films and by thoroughly studying the film microstructure, chemical composition, morphology, piezoelectric response, and mechanical properties before and after annealing. Furthermore, residual stresses were measured using careful X-ray stress analysis (XSA).

\section{METHODS}

\section{A. Thin film deposition}

The AlScN thin films were deposited in a Von Ardenne CS $730 \mathrm{~S}$ system using reactive sputtering at a substrate temperature of $450{ }^{\circ} \mathrm{C}$ using a previously developed process [20]. The films were directly sputtered on $150-\mathrm{mm}$ silicon (100) wafers under a nitrogen and argon atmosphere. The sputtering target was an Al plate with embedded Sc pellets. The targeted Sc-fraction $x$ of the deposited film was $30 \%$ by atomic percentage and the film thickness was $500 \mathrm{~nm}$. This fraction was selected due to availability and because recent $\mathrm{AlScN}$ use in devices was focused around this fraction. At higher fractions, etching of $\mathrm{AlScN}$ becomes difficult [21,22], the crystal quality tends to decrease $[10,17]$ and the elastic constants decrease [23]. The Sc-fraction was confirmed by energy-dispersive $\mathrm{X}$-ray spectroscopy (EDS) using an Oxford Instruments INCA X-sight. The film thickness and refractive index were measured using a Plasmos SD2300 ellipsometer.

\section{B. Annealing}

Samples were annealed in a Webb RD-M vacuum furnace to induce possible changes in the films and determine the temperature threshold for them. Films were annealed at temperatures of $400,600,800$, and $1000^{\circ} \mathrm{C}$ for $5 \mathrm{~h}$. Extended annealing was done at $1000^{\circ} \mathrm{C}$ for up to $300 \mathrm{~h}$. The heating ramp rate was approximately $15^{\circ} \mathrm{C} / \mathrm{min}$ and no active cooling was used. The base pressure before annealing was approximately $0.1 \mathrm{mPa}$. The pressure was monitored during annealing and residual gas analysis (RGA) was performed with an Inficon Transpector MPH analyzer.

\section{Scanning electron, atomic force, and piezoresponse force microscopy}

The surface morphology of the samples was studied using scanning electron (SEM) and atomic force microscopy (AFM). Piezoresponse force microscopy (PFM) was used to study the piezoelectricity of the films. For SEM analysis a Zeiss Supra 40 microscope was used. The AFM measurements were done using a Bruker Dimension Icon in tapping mode and a silicon cantilever tip with a nominal radius of $8 \mathrm{~nm}$. The piezoresponse was measured using a Veeco Multimode AFM with a lock-in amplifier and a platinum-coated tip in contact mode. The drive voltage applied to the sample was $10 \mathrm{~V}$ at a frequency of $11 \mathrm{kHz}$.

\section{X-ray diffraction and stress analysis}

The crystal structure and quality of the $\mathrm{AlScN}$ films were studied using $\mathrm{x}$-ray diffraction (XRD). Symmetrical out-of-plane $2 \theta-\omega$ and in-plane $2 \theta_{\chi}-\phi$ diffractograms, $\omega \mathrm{x}$ ray rocking curves (XRC), and $\chi-2 \theta$ diffraction maps were recorded in a Rigaku SmartLab diffractometer, using $\mathrm{CuK}_{\alpha}$ radiation with wavelengths of $1.54056 \AA$ and $1.54441 \AA$. The $2 \theta-\omega$ diffractograms and $\omega$ XRCs were measured with a parallel beam using a $\mathrm{Ge}(220) \times 2$ monochromator on the incident beam path and a $5^{\circ}$ soller slit on the diffracted beam path. The in-plane measurements were done using a parallel beam and $0.5^{\circ}$ parallel slit collimator on the incident beam path and a $0.5^{\circ}$ parallel slit analyzer on the diffracted beam path. For the diffraction maps, a focused beam was used with a two-dimensional (2D) detector without any optics on the diffracted beam path. The measured $2 \theta-\omega$ and $2 \theta_{\chi}-\phi$ diffractograms were fitted in a least-squares sense using a simple pseudo-Voigt function and the XRCs were fitted using a Gaussian profile.

The residual stress was estimated using XSA. Both the out-of-plane $\varepsilon_{c}$ and in-plane $\varepsilon_{a}$ elastic strains were estimated by measuring the average lattice constant $\langle c\rangle$ using 0002 and 0004 reflections and by measuring the average constant $\langle a\rangle$ using $10 i 0$ and $11 i 0$ reflections. The strains were then calculated by comparing the measured constants to unstrained reference constants $c_{0}$ and $a_{0}$. The in-plane lattice strain analysis was performed under grazing incidence conditions on the 5-circle ETA high-resolution diffractometer using a $\mathrm{CuK}_{\alpha} \mathrm{x}$ ray source, a polycapillary semilens on the incident beam path and a $0.4^{\circ}$ equatorial soller slit, and a $001 \mathrm{LiF}$ monochromator on the diffracted beam path. A scintillation counter was used for data acquisition.

For a biaxial stress state of rotational symmetry, the fundamental equation of XSA reduces to

$$
\varepsilon_{\psi}^{h k i l}=\left(\frac{1}{2} S_{2}^{h k i l} \sin ^{2} \psi+2 S_{1}^{h k i l}\right) \sigma_{\|},
$$




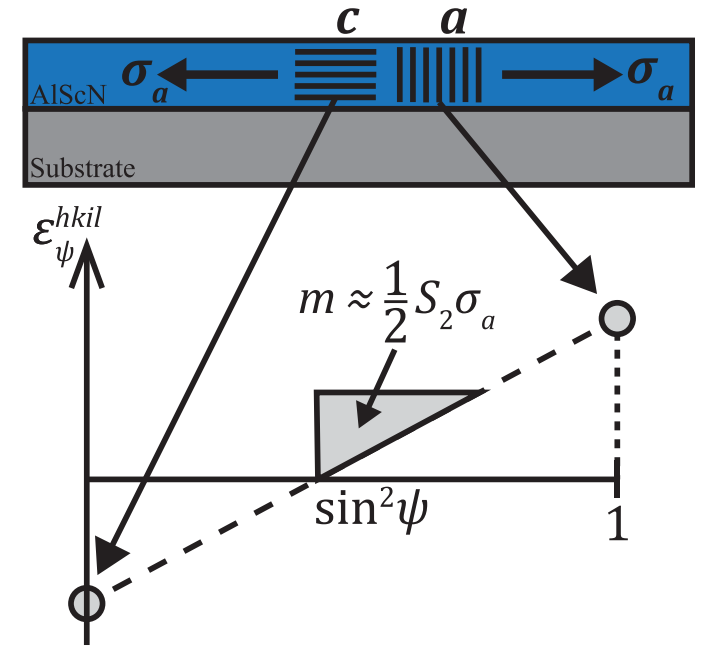

FIG. 1. Stress evaluation by combining out-of-plane and in-plane strains using the $\sin ^{2} \psi$ method.

where $S_{1}$ and $\frac{1}{2} S_{2}$ are diffraction elastic constants (DEC) and $\sigma_{\|}$is the in-plane residual stress. The DECs required for the stress analysis were calculated using the Eshelby/Kröner grain interaction model [24,25] from the single crystal coefficients $c_{i j}$ for $\mathrm{Al}_{0.7} \mathrm{Sc}_{0.3} \mathrm{~N}$ [8]. These constants are related to the direction-dependent Young's modulus $E^{h k i l}$ and Poisson's ratio $v^{\text {hkil }}$ through the following equations:

$$
S_{1}^{h k i l}=\frac{-v^{h k i l}}{E^{h k i l}} \quad \text { and } \quad \frac{1}{2} S_{2}^{h k i l}=\frac{1+v^{h k i l}}{E^{h k i l}} .
$$

Because the AlScN films are expected to be highly (0002) textured, the $\sin ^{2} \psi$-method cannot be used for stress analysis. Instead, the in-plane residual stresses were estimated from the analyzed elastic strains employing four different approaches. (1) Stress evaluation from $\varepsilon_{c}$, (2) evaluation from $\varepsilon_{a}$, (3) combining both $\varepsilon_{c}$ and $\varepsilon_{a}$ using a two-point $\sin ^{2} \psi$ estimate, and (4) evaluation using single-crystal elastic constants. These methods are discussed in more detail in a separate paper and are presented only shortly here.

(1) The biaxial in-plane residual stress $\sigma_{\|}$can be calculated from the measured average lattice constant $\langle c\rangle$ using the following equation:

$$
\sigma_{\|}=\frac{E^{000 l}}{-2 \nu^{000 l}} \frac{\langle c\rangle-c_{0}}{c_{0}} .
$$

(2) Similarly, the residual stress can be calculated using the measured average lattice constant $\langle a\rangle$

$$
\sigma_{\|}=\frac{E^{h k i 0}}{1-v^{h k i 0}} \frac{\langle a\rangle-a_{0}}{a_{0}} .
$$

(3) Both the out-of-plane and in-plane strains can be combined applying the $\sin ^{2} \psi$ method as illustrated in Fig. 1 . A linear function is fitted using the two measured strains at $\psi=0^{\circ}$ and $\psi=90^{\circ}$, and the stress is obtained from its slope as

$$
\sigma_{\|}=\frac{\varepsilon_{90^{\circ}}^{h k i 0}-\varepsilon_{0^{\circ}}^{000 l}}{\frac{1}{2} S_{2}^{h k i 0}+2 S_{1}^{h k i 0}-2 S_{1}^{000 l}} \approx \frac{\Delta \varepsilon}{\left\langle\frac{1}{2} S_{2}\right\rangle},
$$

where $S_{1}^{h k i 0}$ and $S_{1}^{000 l}$ are approximately the same so that $S_{1}^{h k i 0}-S_{1}^{000 l} \approx 0$ and $\Delta \varepsilon$ is the difference between in-plane and out-of-plane strains. Furthermore, due to the hexagonal symmetry and (0002) texture, the films are transverseisotropic and all in-plane crystal directions $h k i 0$ have the same Young's modulus and thus the same $\frac{1}{2} S_{2}$. The approximation for $S_{1}$ is justified later in Sec. III D.

(4) Using the single-crystal elastic constants and assuming plane stress, Hooke's law gives the in-plane stress as

$$
\sigma_{\|}=\left(c_{11}+c_{12}\right) \varepsilon_{a}+c_{13} \varepsilon_{c} .
$$

It is expected that the different methods give different values for the residual stress and their differences are discussed later.

\section{E. Lattice constant simulation}

Because the unstrained lattice constants $a_{0}$ and $c_{0}$ needed for stress analysis are not accurately known for $\mathrm{AlScN}$, they were simulated in this study. $\mathrm{Al}_{1-x} \mathrm{Sc}_{x} \mathrm{~N} 4 \times 4 \times 2$ wurtzite supercells with 128 atoms (64 cations and $64 \mathrm{~N}$ ) were generated by randomly placing Sc and $\mathrm{Al}$ atoms in the cation sublattice for given Sc fractions, ranging from $x=0$ (pure AlN) to $x=0.5$. The supercells were fully relaxed using density functional theory (DFT) as implemented in the Vienna ab initio simulation package (VASP) [26,27]. The exchange-correlation density functional used was PerdewBurke-Ernzerhof (PBE) [28]. All the technical details are given in Ref. [20]. The Sc contents were increased incrementally by four atoms at a time, equivalent to a $6.25 \%$ change in Sc-fraction. Nine random supercells were chosen per composition, where the cations are placed according to different seeds from the random number generator. After full DFT relaxation of the lattice vectors and atomic positions, the resulting supercells are triclinic. To obtain the corresponding hexagonal lattice parameters, a hexagonal projection was performed [29], including the rotational degrees of freedom $[20,30]$.

\section{F. Analytical transmission electron microscopy}

The film microstructure and elemental composition were studied using transmission electron microscopy (TEM) in high-resolution (HRTEM) and scanning (STEM) modes, EDS, and selected area electron diffraction (SAED) in a JEOL JEM-2800 high-resolution microscope, under $200 \mathrm{kV}$ acceleration voltage. Film cross-sections were prepared by focused ion beam (FIB) milling and polishing using Ga-ions. Before FIB milling, layers of platinum were deposited for protection.

\section{G. Fourier transform infrared spectroscopy}

Fourier transform infrared (FTIR) spectroscopy was used to analyze the chemical bonds, preferential orientation, and crystal quality in the as-deposited and annealed films [31-33]. The IR absorbance spectra were measured in a Bruker ALPHA II spectrometer from $400 \mathrm{~cm}^{-1}$ to $4000 \mathrm{~cm}^{-1}$ in transmission mode and at normal incidence. The absorbance spectrum of the Si substrate was subtracted from the measurements. 

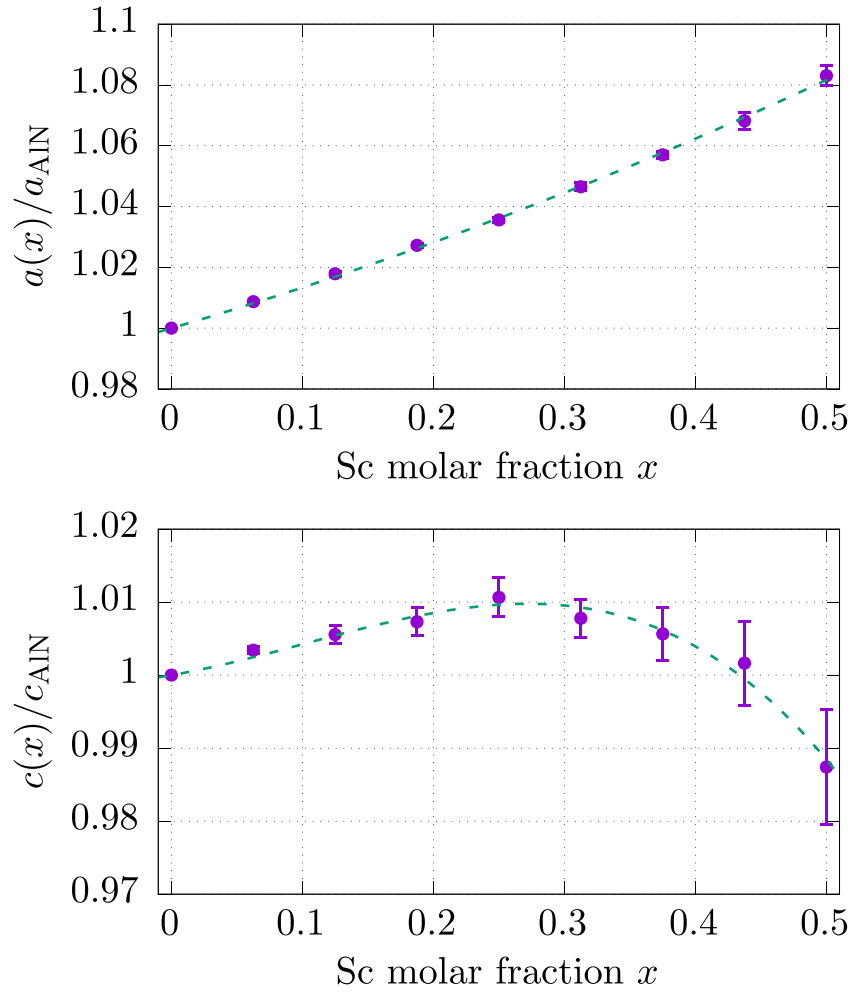

FIG. 2. Simulated lattice constants for $\mathrm{AlScN}$ as a function of Sc-fraction $x$. Solid symbols and error bars represent average values and standard deviation, respectively. Dashed lines give a polynomial fit to the data, quadratic for $a$ and cubic for $c$.

\section{H. Nanoindentation}

Nanoindentation was used to measure the hardness and Young's modulus of the film. The measurements were performed using a Berkovich-type indenter tip and a maximum load of $2 \mathrm{mN}$. The loading and unloading times were $5 \mathrm{~s}$ with a $2 \mathrm{~s}$ hold time between them. The indentation depth was 50-60 nm and Young's modulus and hardness were measured as the average of 20 points. The results were analyzed using the Oliver-Pharr method [34].

\section{RESULTS}

The thickness of the deposited AlScN film was 551(32) $\mathrm{nm}$ with a refractive index of 2.32(17). EDS shows that the Sc-fraction $x$ was approximately 0.35 , with an estimated error of \pm 0.06 . The RGA results do not show any measurable decomposition of $\mathrm{Al}, \mathrm{Sc}$, or $\mathrm{N}$ during annealing. The analysis detected residual $\mathrm{H}_{2} \mathrm{O}, \mathrm{N}_{2}$, and $\mathrm{O}_{2}$ in the furnace during annealing.

\section{A. Unstrained lattice constants}

The unstrained lattice constants as a function of Sc-fraction are presented in Fig. 2. Fitting a polynomial to the simulated results, the expected lattice constants for $\mathrm{Al}_{1-x} \mathrm{Sc}_{x} \mathrm{~N}$ as a function of Sc-fraction $x$ are

$$
\begin{aligned}
& a_{0}(x)=a_{\mathrm{AIN}}\left(1+0.1263 x+0.0740 x^{2}\right), \\
& c_{o}(x)=c_{\mathrm{AIN}}\left(1+0.0309 x+0.1697 x^{2}-0.556 x^{3}\right),
\end{aligned}
$$

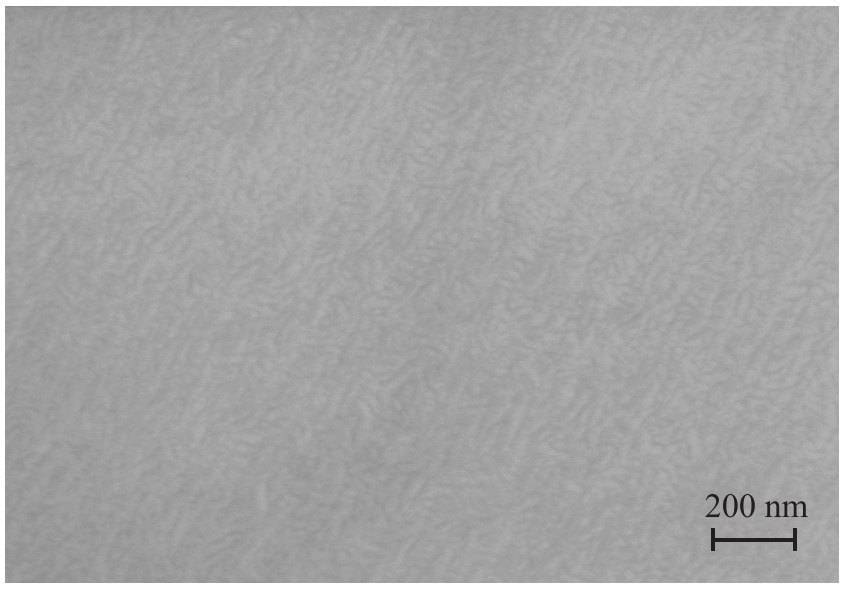

(a)

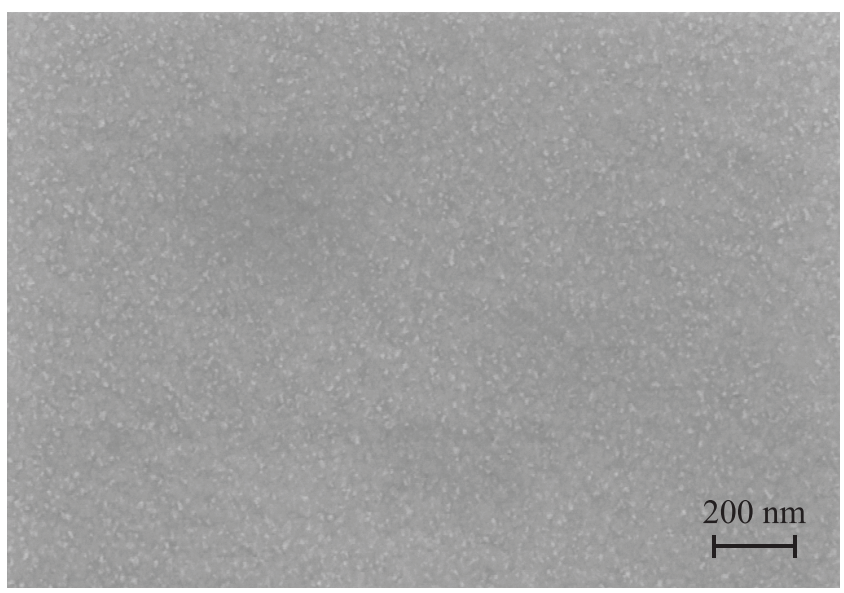

(b)

FIG. 3. SEM micrographs of the surfaces of as-deposited and annealed films. (Contrast and brightness enhanced.) (a) As-deposited film and (b) Film annealed at $1000^{\circ} \mathrm{C}$ for $5 \mathrm{~h}$.

where $a_{\mathrm{AIN}}$ and $c_{\mathrm{AlN}}$ are the unstrained lattice constants for pure AlN.

Using unstrained reference values of $3.11131 \AA$ and $4.98079 \AA$ for AlN [35], the expected lattice constants for $\mathrm{Al}_{0.7} \mathrm{Sc}_{0.3} \mathrm{~N}$ are $a_{0}(0.3)=3.250 \AA$ and $c_{0}(0.3)=5.028 \AA$, with a $c / a$ ratio of 1.547 .

\section{B. Film surface morphology and piezoelectric response}

The surface of the as-deposited film is relatively smooth and featureless, as can be seen in the SEM micrograph in Fig. 3(a). After annealing the film at $1000{ }^{\circ} \mathrm{C}$ for $5 \mathrm{~h}$, small grain-like features can be seen on the surface, as shown in Fig 3(b). No changes to the film surface were observed after annealing at lower temperatures.

The surface grains are observed using AFM as well and they are approximately 4(1) $\mathrm{nm}$ in height and 6(2) nm in diameter after $5 \mathrm{~h}$ of annealing at $1000^{\circ} \mathrm{C}$. The average rootmean-square (rms) surface roughness of the as-deposited film is $1.0(2) \mathrm{nm}$ over an area of $1 \times 1 \mu \mathrm{m}^{2}$ and does not change significantly after $5 \mathrm{~h}$ of annealing at any temperature. However, after $10 \mathrm{~h}$ of annealing at $1000^{\circ} \mathrm{C}$, the surface roughness increases to $1.7(2) \mathrm{nm}$ and remains approximately the same 


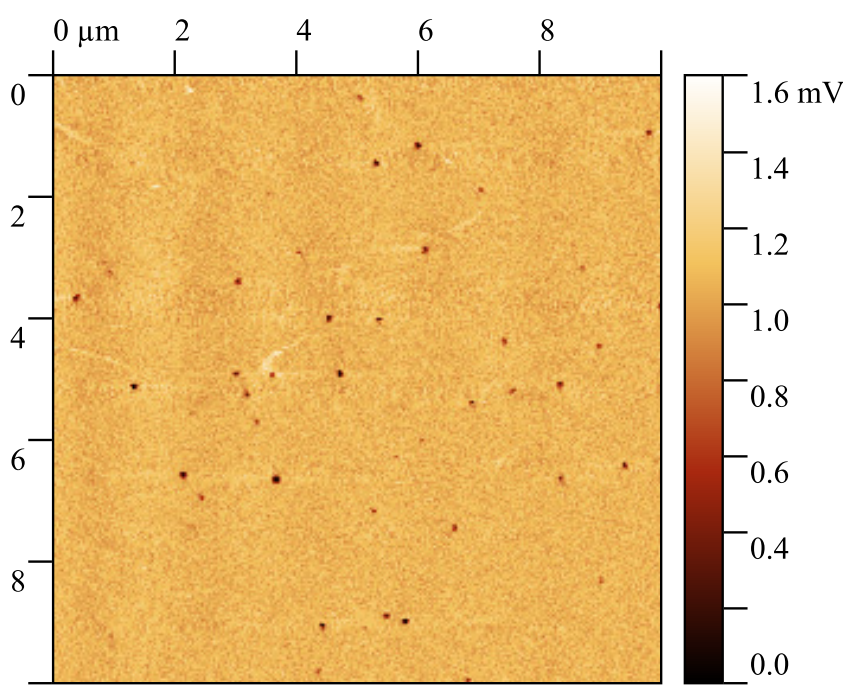

(a)

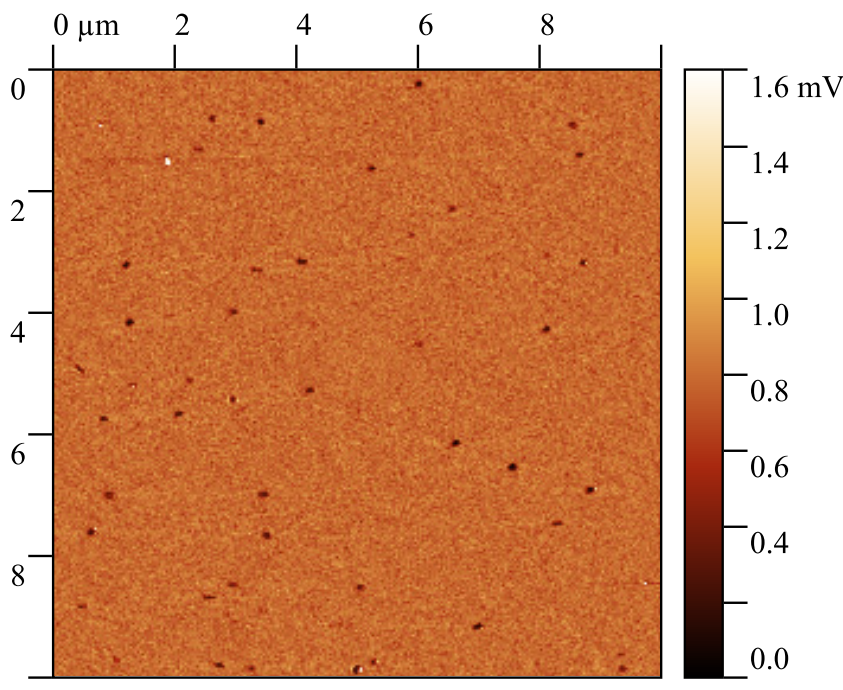

(b)

FIG. 4. The amplitude of the piezoelectric response of the asdeposited and annealed AlScN films. (a) As-deposited film and (b) Film annealed at $1000^{\circ} \mathrm{C}$ for $5 \mathrm{~h}$.

during further annealing. Moreover, the surface grains seem to grow laterally, and their diameter is $10 \pm 3 \mathrm{~nm}$ after $10 \mathrm{~h}$ of annealing, while their height remains approximately the same. The size of the grains remains approximately constant during further annealing.

The piezoelectric response was compared between the asdeposited film and the film annealed at $1000{ }^{\circ} \mathrm{C}$ for $5 \mathrm{~h}$ with the observed surface grains. No significant changes were detected in the amplitude or phase of the piezoelectric response. Figure 4 presents the measured piezoelectric amplitudes over a $10 \times 10 \mu \mathrm{m}^{2}$ area for both films. The films seem to contain small regions that do not exhibit piezoelectric properties, which are seen as black spots in Fig. 4.

\section{Microstructure}

Measured $\chi-2 \theta$ diffraction maps are presented in Fig. 5 for the as-deposited film [Fig. 5(a)] and the film annealed

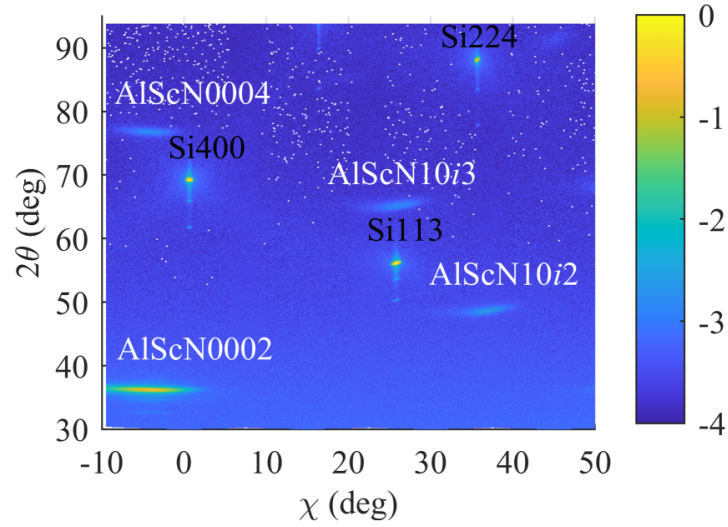

(a)

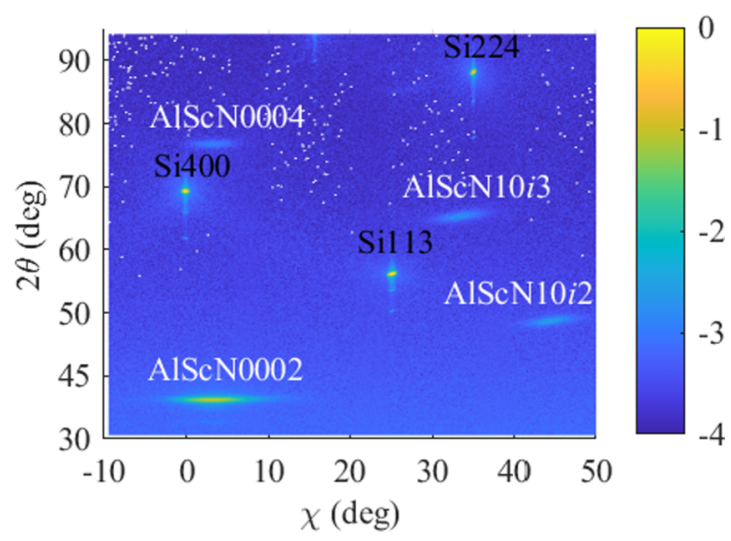

(b)

FIG. 5. Measured $\chi-2 \theta$ x-ray diffraction maps of as-deposited and annealed films. The measured intensity is normalized to the Si113 peak in each map and a logarithmic scale is used to present the intensity. AlScN reflections are labeled in white and substrate reflections in black. (a) As-deposited film and (b) Film annealed at $1000^{\circ} \mathrm{C}$ for $5 \mathrm{~h}$.

at $1000^{\circ} \mathrm{C}$ for $5 \mathrm{~h}$ [Fig. 5(b)]. All the detected reflections correspond to a (0002) textured $\mathrm{AlScN}$ on a $\mathrm{Si}(100)$ substrate with no new crystalline phases. The XRD maps show a tilt between the $\mathrm{AlScN}$ [0002] and $\mathrm{Si}[400]$ of up to $5^{\circ}$, depending on where on the wafer the sample was taken. The grains seem to be tilted towards the center of the wafer and the tilt seems to increase towards the wafer edge.

TABLE I. Location and full width at half maximum (FWHM) of the AlScN 0002 reflection, and the FWHM of the 0002 XRC of the films before and after annealing at $400-1000^{\circ} \mathrm{C}$ for $5 \mathrm{~h}$.

\begin{tabular}{lccc}
\hline \hline $\begin{array}{l}\text { Annealing } \\
\text { temp. }\left({ }^{\circ} \mathrm{C}\right)\end{array}$ & $2 \theta\left(^{\circ}\right)$ & $\begin{array}{c}2 \theta-\omega \\
\text { FWHM }\left({ }^{\circ}\right)\end{array}$ & $\begin{array}{c}\omega \text { XRC } \\
\text { FWHM }\left(^{\circ}\right)\end{array}$ \\
\hline As-dep. & 36.1 & 0.34 & 3.36 \\
400 & 36.2 & 0.35 & 3.47 \\
600 & 36.2 & 0.35 & 3.26 \\
800 & 36.2 & 0.29 & 3.01 \\
1000 & 36.2 & 0.34 & 3.06 \\
\hline \hline
\end{tabular}




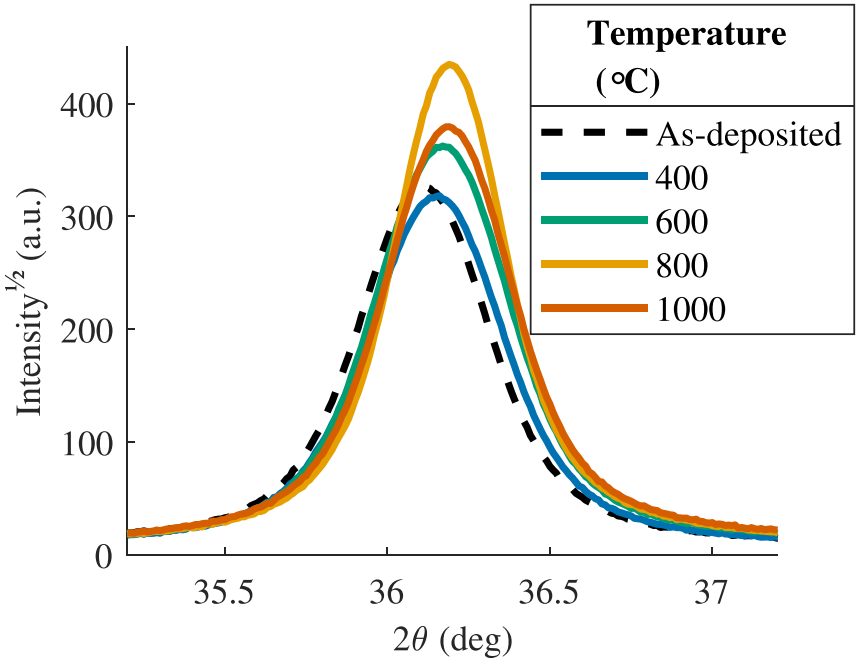

(a)

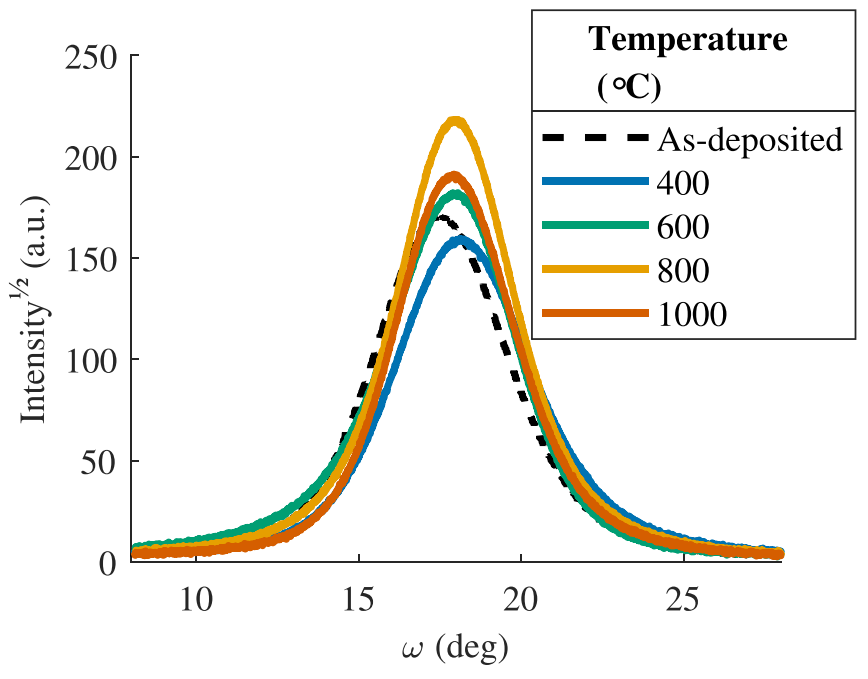

(b)

FIG. 6. XRD results for as-deposited film and films annealed at $400{ }^{\circ} \mathrm{C}-1000{ }^{\circ} \mathrm{C}$ for $5 \mathrm{~h}$. The square root of the intensity is used for visualization purposes. (a) Measured $2 \theta-\omega$ diffractograms of the 0002 reflection and (b) X-ray rocking curves about the 0002 reflection.

The $2 \theta-\omega$ XRD results are summarized in Table I and show that annealing increases the crystal quality, reaching a maximum at $800{ }^{\circ} \mathrm{C}$. The quality does not change significantly at temperatures below $800^{\circ} \mathrm{C}$. The measured $2 \theta-\omega$ diffractograms of the 0002 reflection are presented in Fig. 6(a), and Fig. 6(b) presents XRCs about the same reflection. No other diffraction peaks were detected. The results for the location of the 0002 reflection seem to suggest that annealing decreases the lattice constants $c$, which in turn means increased biaxial tensile stress. However, this is not the case as is shown in Sec. III D.

The TEM analysis shows some changes in the film microstructure after annealing at $1000^{\circ} \mathrm{C}$. Figures 7 (a) and 7(b) present cross-sectional STEM micrographs for as-deposited and annealed film, respectively. Electron diffraction shows no new crystalline phases after $10 \mathrm{~h}$ of annealing at $1000^{\circ} \mathrm{C}$.

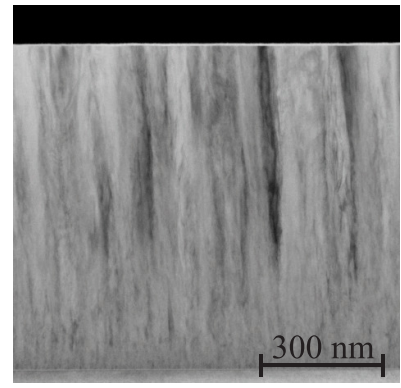

(a)

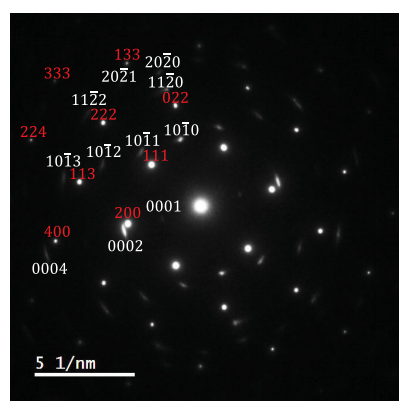

(c)

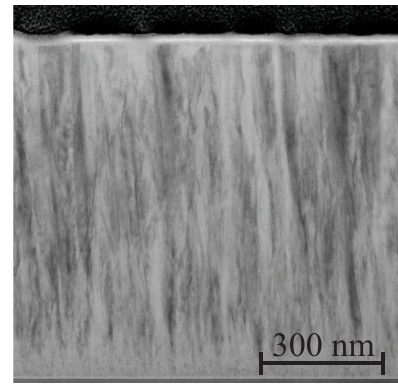

(b)

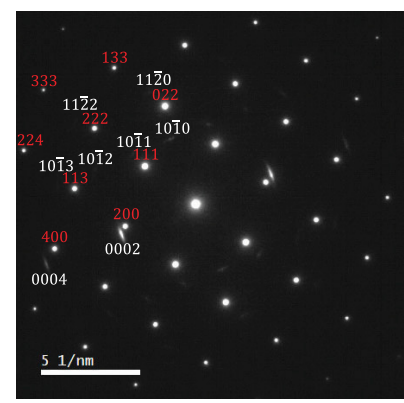

(d)

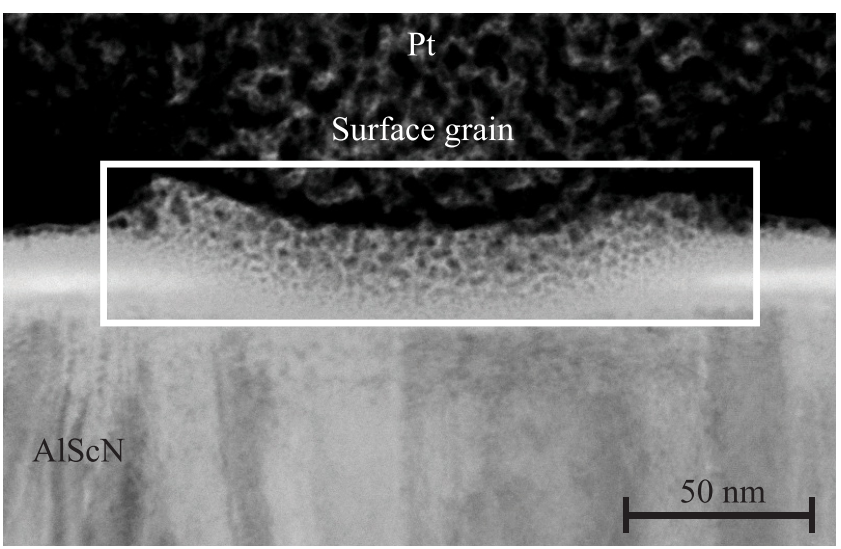

(e)
FIG. 7. TEM analysis of AlScN films before (left) and after annealing at $1000^{\circ} \mathrm{C}$ for $10 \mathrm{~h}$ (right). (a), (b) Cross-sectional STEM micrographs. (c), (d) SAED patterns. The AlScN spots are labeled in white and the Si spots in red. Contrast and brightness enhanced. (e) Cross-sectional STEM micrograph of a grain at the surface of the $\mathrm{AlScN}$ film after annealing.

SAED patterns recorded along the $\mathrm{Si}[0 \overline{1} 1]$ zone axis are presented in Figs. 7(c) and 7(d) for as-deposited and annealed film, respectively. The selected area contained the full thickness of the $\mathrm{AlScN}$ film and part of the Si substrate. The tilt between $\mathrm{AlScN}$ [0002] and $\mathrm{Si}[400$ ] seen in the XRD maps is observed in the SAED patterns as well and is approximately $4.5^{\circ}$ in these films. The $\mathrm{AlScN}$ film does not have preferential in-plane orientation with respect to the substrate, as evidenced by the excitation of both the $10 \overline{1} 0$ and $11 \overline{2} 0$ spots. The lattice constants of the as-deposited AlScN are $a=3.3 \AA$ and $c=5.0 \AA$ measured from the SAED patterns using the $\mathrm{SiO04}$ diffraction spot as a reference and assuming a lattice 
constant of $5.431 \AA$ for Si. The measured lattice constants correspond to biaxial tensile stress. The estimated error in the lattice constants measured from SAED patterns is $0.1 \AA$.

The grains on the film surface observed under SEM and AFM are seen in TEM as well and they are limited to the surface of the film, as can be seen in the STEM micrograph in Fig. 7(e). The thickness of the grains is approximately $20 \mathrm{~nm}$. The surface grains do not have an ordered crystal structure and are mostly amorphous with small polycrystalline regions, where lattice fringes are visible under HRTEM.

EDS elemental maps do not show elemental segregation of $\mathrm{Al}$ and $\mathrm{Sc}$ after $10 \mathrm{~h}$ of annealing at $1000^{\circ} \mathrm{C}$, within the approximately 5-nm spatial resolution of the STEM/EDS elemental maps. However, the TEM cross-sections and EDS analysis show a thin native oxide $(\mathrm{AlScO})$ layer at the surface of the as-deposited film. After $10 \mathrm{~h}$ of annealing at $1000^{\circ} \mathrm{C}$, a second layer formed on top of the native oxide and it can be seen as a gray layer in Fig. 7(e). The new layer is an oxide as well and seems to contain more Sc than the native oxide. Interestingly, the surface grains seem to be growing from the AlScN film and through the native oxide and on top of the Sc-rich oxide layer. Fast Fourier transforms (FFT) of the HRTEM micrographs show that the new layer on top of the film surface is polycrystalline and has a spacing of $2.1 \AA$ between the lattice fringes.

Annealing at $1000^{\circ} \mathrm{C}$ was continued for up to $300 \mathrm{~h}$ since this was the only temperature at which significant changes were observed. Figure 8 (a) presents a $\chi-2 \theta$ diffraction map after $300 \mathrm{~h}$ of annealing and shows increased reflected intensity on the high-angle side of the 0002 reflection. Figure $8(\mathrm{~b})$ presents the XRD $2 \theta-\omega$ diffractogram of film annealed at $1000^{\circ} \mathrm{C}$ for $300 \mathrm{~h}$. Two additional peaks seem to have formed on both sides of the AlScN0002 peak and a sum of three pseudo-Voigt functions $\left(f_{1}, f_{2}\right.$, and $\left.f_{3}\right)$ was necessary to explain the diffractogram. The three different functions are shown as orange dashed lines in Fig. 8(b). The first peak $\left(f_{1}\right)$ is centered around a $2 \theta$ angle of $35.71^{\circ}$ and the third $\left(f_{3}\right)$ around $38.91^{\circ}$. The peak detected at $2 \theta=33^{\circ}$ is the forbidden Si200 reflection from the substrate [36]. Similarly, additional peaks were observed around the main 0002 peak after annealing for $100 \mathrm{~h}$ and $200 \mathrm{~h}$ at $1000^{\circ} \mathrm{C}$ and their intensity increases with annealing time.

The changes in the diffractogram might be caused by differently strained crystallites, the formation of new crystalline phases, or by a combination of both. The film annealed at $1000^{\circ} \mathrm{C}$ for $300 \mathrm{~h}$ was further studied using in-plane XRD in order to determine the cause of the changes. Figure 8(c) presents a $2 \theta_{\chi}-\phi$ diffractogram from $30^{\circ}$ to $90^{\circ}$, which shows the $10 i 0,11 i 0$, and $20 i 0$ reflections for as-deposited and annealed AlScN. In addition to the AlScN reflections becoming broader, similarly to the 0002 reflection, five new peaks seem to be present in the diffractogram. The new reflections are at $2 \theta_{\chi}$ angles of $40.41,46.92,68.87,83.25$, and $87.53^{\circ}$. Depth profiling shows that the new reflections come from deeper in the film than the AlScN reflections. The profiling is done by adjusting the angle between the sample surface and the incident beam and shows that the additional peaks have maxima at an angle of $1.4^{\circ}$, whereas the $10 i 0$ peak has a maximum at an angle of $0.4^{\circ}$. The as-deposited film has one unidentified reflection around $40^{\circ}$ as well.

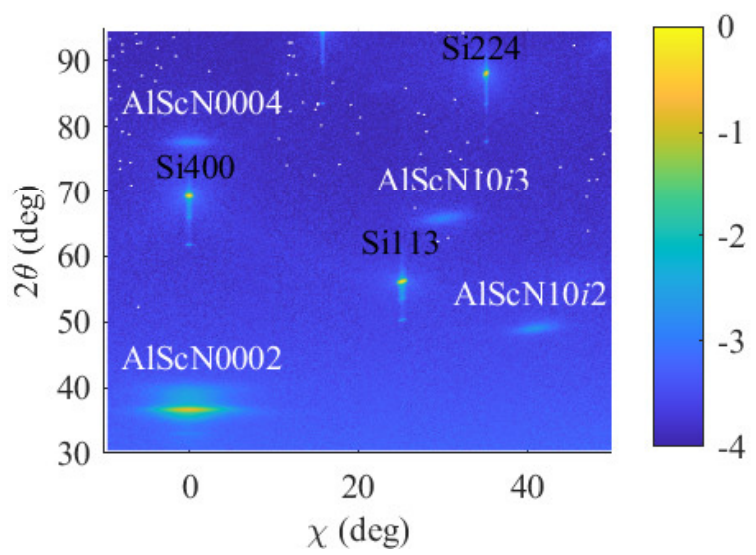

(a)

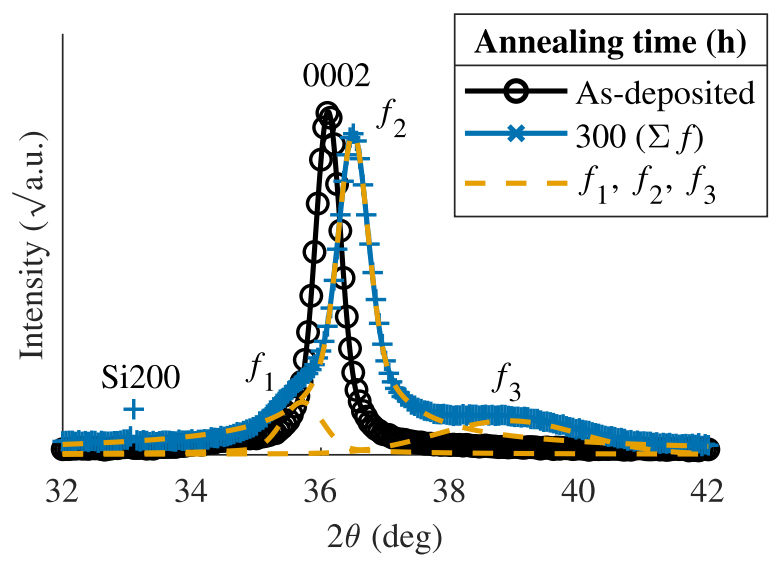

(b)

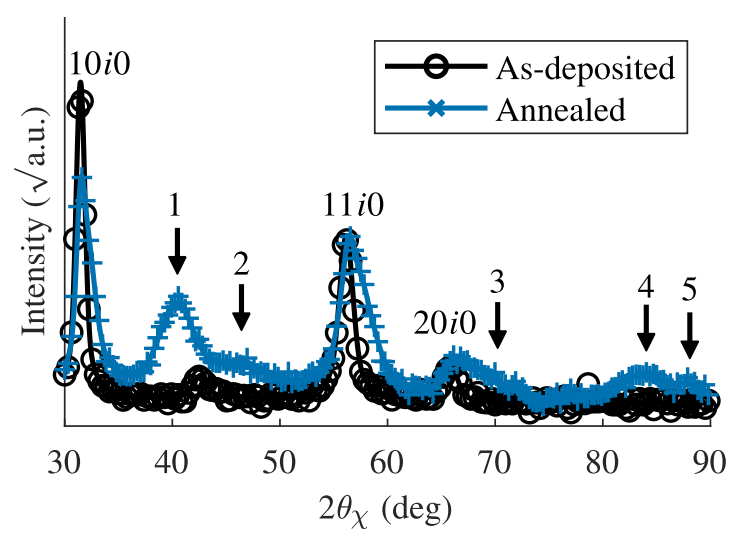

(c)

FIG. 8. XRD results of film annealed at $1000^{\circ} \mathrm{C}$ for $300 \mathrm{~h}$. (a) A $\chi-2 \theta$ diffraction map. Intensity is normalized to Si113 peak and presented using a logarithmic scale. AlScN reflections in white and $\mathrm{Si}$ in black. (b) Out-of-plane XRD of the AlScN 0002 reflection. The three components $f_{1-3}$ of the pseudo-Voigt sum are shown as orange dashed lines. (Only every fifth measurement plotted for clarity.) (c) In-plane XRD of the $\mathrm{AlScN} 10 i 0,11 i 0$ and $20 i 0$ reflections. New reflections are highlighted with arrows. (Only every fortieth measurement plotted for clarity.) The vertical axis in the diffractograms presents the square root of the intensity for visualization purposes. 


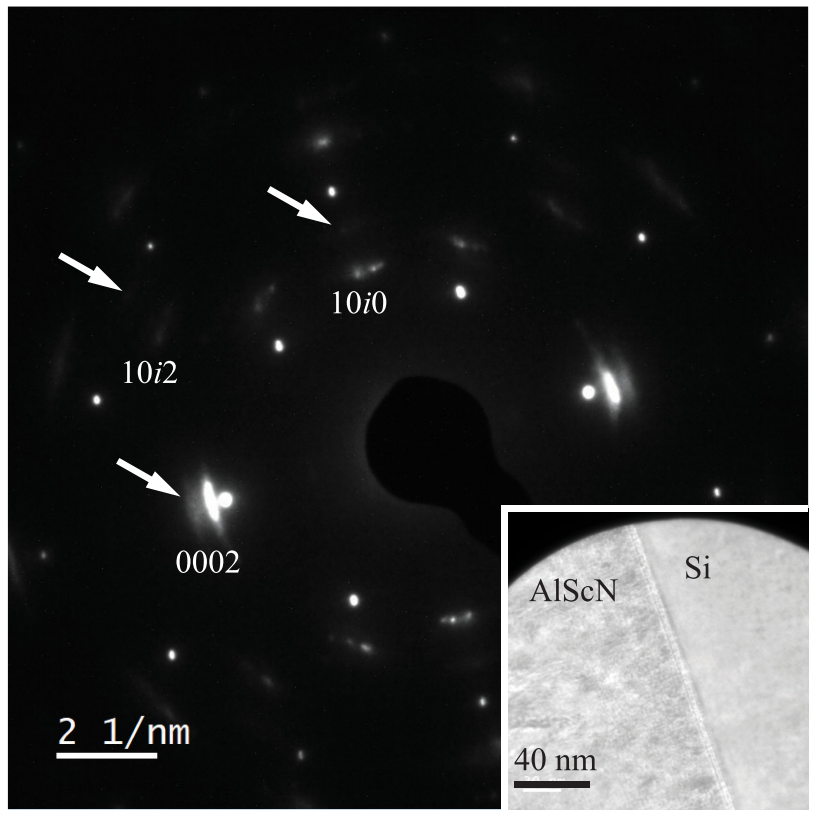

(a)

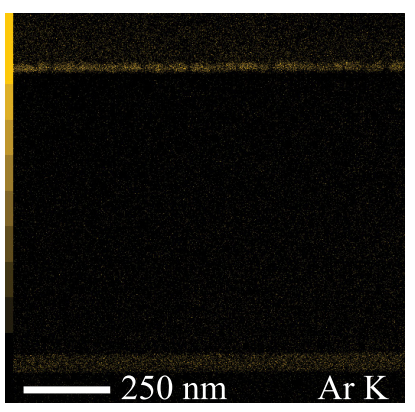

(b)

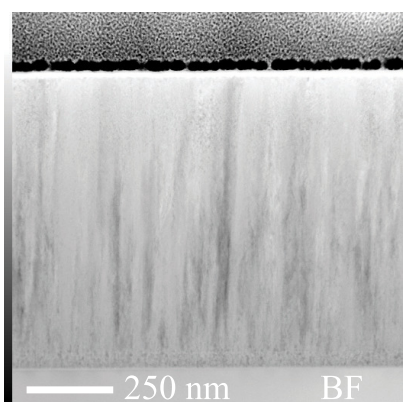

(c)
FIG. 9. TEM results of AlScN film after annealing at $1000^{\circ} \mathrm{C}$ for $300 \mathrm{~h}$. (a) SAED pattern, the selected area is near the film-substrate interface, shown in the inset. New diffraction spots next to 0002 , $10 i 0$, and $10 i 2$ are highlighted with arrows, (b) EDS map of the $\mathrm{Ar}$ K-line intensity, showing the excess Ar concentration near the filmsubstrate interface, and (c) BF STEM micrograph for EDS mapping in panel (b).

New diffraction spots are observed in SAED patterns as well, as what seems to be splitting of the 0002 and $10 i 0$ diffraction spots into two, shown in Fig. 9(a). The 0002 spots correspond to the detected XRD peaks at $36.50^{\circ}\left(f_{2}\right)$ and $38.91^{\circ}\left(f_{3}\right)$. No diffraction spot is seen for the XRD peak at $35.71^{\circ}\left(f_{1}\right)$, likely because the separation is too small from the main 0002 diffraction spot. The $10 i 0$ spot and the split spot next to it correspond to the detected in-plane XRD peaks at $31.51^{\circ}$ and $41.41^{\circ}$. SAED shows that the splitting of the $10 i 0$ and 0002 diffraction spots occurs near the film-substrate interface, whereas near the surface there is no split (or only split of $10 i 0$ as seen in HRTEM FFT). In addition to the splitting of the diffraction spots, an Ar rich layer has formed near the film-substrate interface, as seen in the EDS map in Fig. 9(b). The Ar rich layer was not observed in the as-deposited film or the film annealed at $1000^{\circ} \mathrm{C}$ for $10 \mathrm{~h}$. The values for the
TABLE II. Values for the main and split lattice constants $a$ and $c$ measured using SAED and XRD for AlScN film annealed at $1000^{\circ} \mathrm{C}$ for $300 \mathrm{~h}$.

\begin{tabular}{lccccc}
\hline \hline \multirow{2}{*}{ Method } & \multicolumn{2}{c}{$a(\AA)$} & & \multicolumn{2}{c}{$c(\AA)$} \\
\cline { 2 - 3 } \cline { 6 - 6 } & Main & Split & & Main & Split \\
\hline SAED & 3.3 & 2.6 & & 4.9 & 4.5 \\
XRD & 3.3 & 2.6 & & 4.9 & 4.6 \\
\hline \hline
\end{tabular}

measured lattice constants are in good agreement between SAED and XRD and are presented in Table II, assuming that the split reflections are from wurtzite AlScN. The estimated error is $0.1 \AA$, using the width of the Si200 diffraction spot.

The FTIR absorbance spectra did not change significantly when annealed below temperatures of $1000^{\circ} \mathrm{C}$. The only observed absorbance bands are centered around $624 \mathrm{~cm}^{-1}$, which is most likely the AlN $\mathrm{E}_{1}$ transverse optical (TO) band $\left(672 \mathrm{~cm}^{-1}\right.$ for AlN [32]) shifted down to a lower wave number due to Sc content. No $\mathrm{A}_{1}$ (TO) bands were detected, which confirms that the films do not have grains of mixed orientation [31]. The wave number, FWHM, and intensity of the measured $E_{1}(\mathrm{TO})$ bands after annealing are summarized in Table III and indicate that the crystal quality improved as a result of annealing. The $E_{1}$ (TO) bands were asymmetrical, likely due to the multiphonon modes affecting the high wave-number side [37]. This asymmetry was taken into account by using a split Lorentz function for the low and high wave-number sides of the band. The $E_{1}(\mathrm{TO})$ band FWHM in Table III was defined using the low wave-number side and the asymmetry is measured as the ratio between the difference and sum of the FWHMs of both sides.

After annealing at $1000^{\circ} \mathrm{C}$ the $E_{1}(\mathrm{TO})$ band intensity decreased and asymmetry increased compared to the asdeposited, and new absorbance bands emerged, as can be seen in Fig. 10. The most significant band is at $1380 \mathrm{~cm}^{-1}$ and it is commonly associated with the $\mathrm{CH}_{2}$ or $\mathrm{N}-\mathrm{O}$ bending group. The absorbance bands at $400-500 \mathrm{~cm}^{-1}$ might be an indication of the formation of $\mathrm{ScO}_{x}$ [38].

\section{Residual stress, hardness, and effective Young's modulus}

The DECs $S_{1}^{h k i l}$ and $\frac{1}{2} S_{2}^{h k i l}$ calculated using the Eshelby/Kröner grain interaction model are presented in Table IV. The DECs $S_{1}^{h k i 0}$ and $S_{1}^{000 l}$ are approximately the same, justifying the approximation used in Eq. (5).

TABLE III. The location, FWHM, intensity, and asymmetry of the $\mathrm{AlScN} E_{1}(\mathrm{TO})$ absorption band as determined by the Lorentzian fit after annealing the films at various temperatures for $5 \mathrm{~h}$.

\begin{tabular}{lcccc}
\hline \hline $\begin{array}{l}\text { Annealing } \\
\text { temp. }\left({ }^{\circ} \mathrm{C}\right)\end{array}$ & $\begin{array}{c}\text { Wavenumber } \\
\left(\mathrm{cm}^{-1}\right)\end{array}$ & $\begin{array}{c}\text { FWHM } \\
\left(\mathrm{cm}^{-1}\right)\end{array}$ & $\begin{array}{c}\text { Intensity } \\
(\mathrm{a} . \mathrm{u})\end{array}$ & Asymmetry \\
\hline As-dep. & 622.05 & 91.42 & 1.32 & -0.28 \\
400 & 623.42 & 92.63 & 1.32 & -0.25 \\
600 & 623.44 & 89.21 & 1.36 & -0.27 \\
800 & 624.63 & 88.70 & 1.39 & -0.27 \\
1000 & 624.06 & 85.62 & 1.27 & -0.31 \\
\hline \hline
\end{tabular}




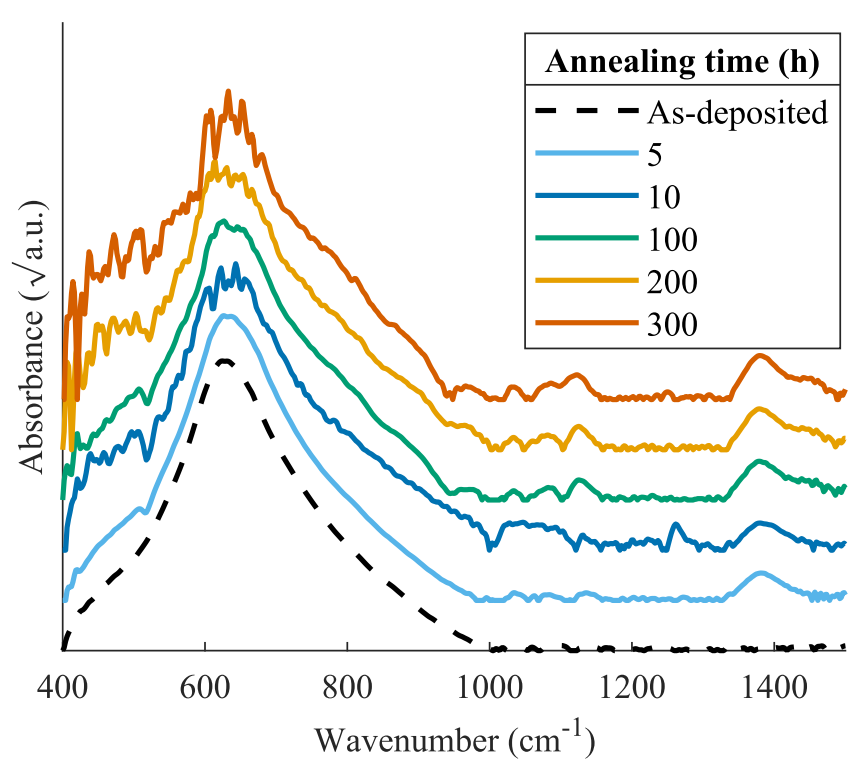

FIG. 10. FTIR absorbance spectra for the as-deposited film and films annealed at $1000^{\circ} \mathrm{C}$. Intensity presented as a square root for visualization purposes.

The estimated residual stresses are presented in Table $\mathrm{V}$ calculated using the four different methods, shortly described in Sec. II D. While the absolute values depend on the method used, they all show that the residual stress decreased as a result of annealing.

The nanoindentation results are summarized in Table VI and show small changes in Young's modulus and hardness of the films as a result of annealing. The statistical significance of the change is estimated using Student's $t$-test [39]. The Poisson ratio was estimated to be 0.280 [40], using the elastic constants for $\mathrm{Al}_{0.7} \mathrm{Sc}_{0.3} \mathrm{~N}$ [8].

\section{DISCUSSION}

The three main changes observed in the AlScN films as a result of annealing were the change in the film microstructure, the relaxation of average residual tensile stresses, and the formation of surface grains. The microstructural changes were observed as a change in the crystal quality and Ar segregation into grain boundaries. Short annealing increased the crystal quality and the best quality was reached at a temperature of $800^{\circ} \mathrm{C}$. The FTIR results seem to indicate that the maximum crystal quality was reached at a temperature of $1000^{\circ} \mathrm{C}$, while XRD results indicate $800^{\circ} \mathrm{C}$. The difference might be explained by the asymmetry of the $E_{1}(\mathrm{TO})$ absorption band, which increased after annealing at $1000^{\circ} \mathrm{C}$ and masked some of the increase in the width of the band. The increase in the

TABLE IV. Diffraction elastic constants for $\mathrm{Al}_{0.7} \mathrm{Sc}_{0.3} \mathrm{~N}$.

\begin{tabular}{lll}
\hline \hline & \multicolumn{2}{c}{ Constant $\left(10^{-6} \mathrm{MPa}^{-1}\right)$} \\
\cline { 2 - 3 } Direction & $S_{1}$ & $\frac{1}{2} S_{2}$ \\
\hline hki0 & -1.42 & 5.92 \\
$000 l$ & -1.52 & 6.81 \\
\hline \hline
\end{tabular}

TABLE V. Residual stress in the AlScN film before and after annealing at $1000^{\circ} \mathrm{C}$ for $5 \mathrm{~h}$, calculated using the four different methods described in Sec. IID. The last row is the change $\Delta$ in the measured residual stress.

\begin{tabular}{lcccc}
\hline \hline \multirow{4}{*}{ Sample } & \multicolumn{4}{c}{ Stress $\sigma_{a}(\mathrm{GPa})$} \\
\cline { 2 - 5 } & Eq. (3) $\varepsilon_{c}$ & Eq. (4) $\varepsilon_{a}$ & Eq. (5) $\Delta \varepsilon$ & Eq. (6) $c_{i j}$ \\
\hline As-deposited & 3.6 & 2.3 & 2.8 & 1.8 \\
Annealed & 2.5 & 1.1 & 1.8 & 1.4 \\
$\Delta$ & -1.1 & -1.2 & -1.0 & -0.4 \\
\hline \hline
\end{tabular}

asymmetry could have been caused by the change in the strain distribution, instead of multiphonon modes. For the XRD measurements, the tilt of the (0002) planes caused some difficulty in aligning the goniometer, which could lead to some error in the analysis. To increase the reliably of the results, the goniometer was aligned carefully to the 0002 maxima for each sample.

The crystallite size in the as-deposited film seems to change during deposition as the film grows in thickness. Within approximately the first $50 \mathrm{~nm}$ of the film, the crystallites are small and round, only up to $10 \mathrm{~nm}$ in diameter. Moreover, these crystallites have lower crystallinity compared to the rest of the film. After the first $50 \mathrm{~nm}$, the growth mode changes to columnar growth, and the columnar crystallites reach the film surface and the crystallinity improves as well. Annealing did not seem to change the crystallite size or shape.

While annealing did not affect the crystallite size or shape significantly, it did cause Ar used in sputtering to segregate to the grain boundaries. Excess Ar was only detected in the small crystallite size region near the substrate in EDS maps. However, Ar likely segregates to all grain boundaries, including the ones between columnar crystallites. The number of Ar atoms in the columnar growth region is not enough for detection, whereas in the small crystallite region there are more grain boundaries and thus more Ar atoms.

The excess Ar atoms in the grain boundaries between the columnar grains are likely the source of the $\mathrm{AlScN}$ reflection broadening. The broadening is seen as a shoulder on the low-angle side of the 0002 reflection, indicating that the lattice constant $c$ has increased, whereas the $h k i 0$ reflections have the shoulders on the high-angle sides, indicating that the lattice constant $a$ has decreased. The simultaneous increase of $c$ and decrease of $a$ corresponds to a biaxial strain that is more compressive relative to the main peak. The new biaxial strain component is present in the columnar grains because

TABLE VI. Young's modulus and hardness of the as-deposited film and film annealed at $1000^{\circ} \mathrm{C}$ for $5 \mathrm{~h}$. On the last row is the $p$-value of the $t$-test, indicating the probability that there is no difference in Young's modulus or hardness.

\begin{tabular}{lcc}
\hline \hline Sample & $\begin{array}{c}\text { Young's modulus } \\
(\mathrm{GPa})\end{array}$ & $\begin{array}{c}\text { Hardness } \\
(\mathrm{GPa})\end{array}$ \\
\hline As-deposited & $117.0 \pm 4.6$ & $14.8 \pm 0.9$ \\
Annealed & $113.1 \pm 5.0$ & $13.7 \pm 0.7$ \\
$p$-value & 0.0183 & 0.0002 \\
\hline \hline
\end{tabular}


they have mostly vertical grain boundaries, and the excess $\mathrm{Ar}$ atoms thus exert mostly lateral forces. Interestingly, the locations of the shoulders seem to correspond to the simulated strain-free lattice constants within a few percent.

The new reflections and diffraction spots are caused by either triaxial compressive strain or more likely by the formation rock-salt phase. Phase transformation of some of the small wurtzite crystallites near the substrate into the rocksalt structure would explain all the new XRD reflections and SAED spots. The peak at $2 \theta_{x}=40.41^{\circ}$ would be the rock-salt 111 reflection and the rest of the peaks would be the 200, 220, 311 , and 222. Using all of these reflections, the average lattice constant $a$ of the rock-salt structure is 3.861(9) $\AA$.

It seems that the rock-salt 111 reflection is observed even in the as-deposited film. In the early stages of grain growth, the stress tends to be compressive before cluster coalescence occurs due to surface stresses in the clusters [41]. It is then hypothesized that the compressive stress in the clusters causes rock-salt $\mathrm{AlScN}$ to form instead of wurtzite. Thus small crystallites of rock-salt $\mathrm{AlScN}$ might form always during the early stages of sputter deposition and they continue to grow when annealed at sufficiently high temperatures. This would mean that no spinodal decomposition or nucleation is required during annealing for the formation of more rock-salt AlScN.

The new rock-salt crystallites formed during annealing would most likely be compressively strained as well. Using Vegard's rule [42] and lattice constants of $4.045 \AA$ and $4.500 \AA$ for rock-salt AlN [43] and ScN [44], respectively, the approximated lattice constant of rock-salt $\mathrm{Al}_{0.7} \mathrm{Sc}_{0.3} \mathrm{~N}$ is $4.182 \AA$. The difference between the lattice constants is approximately $-7.68(22) \%$. This approximation, of course, assumes the lattice constants of AlN and $\mathrm{ScN}$, and that Vegard's rule holds for rock-salt AlScN, which might not be the case especially for high Sc-fractions.

If the rock-salt crystallites were randomly oriented, the 200 reflection should be the most intense one according to the structure factors. However, in the measurement, the 111 seems to be the most intense reflection. This would mean preferential 111 orientation of the crystallites and some additional randomly oriented ones. In the out-of-plane XRD, the only detected reflection would be again the 111 , which is at a slightly smaller angle of $38.91^{\circ}$. No other reflections were detected, even when using maximum possible beam intensity (no monochromator, widest possible slits). The presence of the 111 reflection in both out-of-plane and in-plane XRD geometries would mean that there are two sets of crystallites with preferential 111 orientation because the reflections themselves cannot be at perpendicular angles. The perpendicular 111 reflections would then correspond to the additional diffraction spots near the 0002 and $10 i 0$ spots in Fig. 9(a). The out-of-plane strain of the rock-salt crystallites would be compressive and approximately $-4.2 \%$.

An alternative explanation for the new XRD reflections and SAED spots would be compressive triaxial strain near the film-substrate interface where the crystallites are small and round. In this case, the resulting strain induced by the excess Ar atoms in the grain boundaries would be triaxial instead of biaxial because the compression is uniform around the crystallites. Moreover, the ratio of grain boundaries to volume is larger in this region as well, resulting in increased

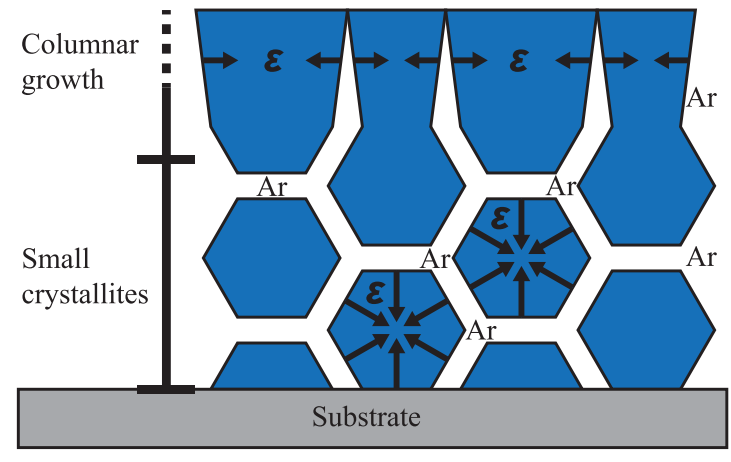

FIG. 11. Schematic of Ar segregation-induced strain in AlScN crystallites in the small crystallite and columnar growth regions.

strain compared to the columnar growth region. Figure 11 illustrates how the strain induced by the excess Ar atoms would depend on the local microstructure. The out-of-plane and in-plane components of the triaxial strain would be approximately $8 \%$ and $19 \%$, respectively, when compared to the simulated reference lattice constants. This, in turn, would correspond to compressive stresses in excess of $60 \mathrm{GPa}$, which is enormously high. Moreover, since the rest of the film is still in tensile stress, this would mean a stress gradient in the order of hundreds of GPa per $1 \mu \mathrm{m}$, which does not seem feasible.

In conclusion, annealing caused most likely the formation or growth of rock-salt AlScN crystallites with preferential 111 orientation or enormous triaxial compressive strains in the small wurtzite AlScN crystallites. Both explanations are presented here for completeness since both require some assumptions to be made. Since it was hypothesized that compressive strains could destabilize the wurtzite phase and lead to the formation of the rock-salt phase either directly or through spinodal decomposition, the observed results may be a convolution of both explanations. In other words, there are triaxial compressive strains present in the small crystallites and as a result of the compression, some of them have transformed into the rock-salt phase.

The average biaxial residual stress changed as a result of annealing and the XSA measurements give the average tensile stress in the range of 1.8-3.6 GPa, depending on the evaluation method employed, after deposition directly on $\mathrm{Si}(100)$ substrate. Even after $5 \mathrm{~h}$ of annealing at $1000^{\circ} \mathrm{C}$, the stress decreased by approximately $1 \mathrm{GPa}$, down to $1.1-2.5 \mathrm{GPa}$. Even though the residual stresses decreased by a significant amount as a result of annealing, they can still be considered high.

Extrinsic stresses alone are likely not enough to explain the high observed residual stresses and the reduction in them after annealing. The residual stress caused by the difference between the coefficients of thermal expansion (CTE) of AlScN and $\mathrm{Si}$ is approximately less than $200 \mathrm{MPa}$, assuming CTEs of $4.84 \times 10^{-6} \mathrm{~K}^{-1}$ and $3.60 \times 10^{-6} \mathrm{~K}^{-1}$ for AlScN [13] and $\mathrm{Si}$ [45], respectively, and that they remain constant over the temperature range from $450^{\circ} \mathrm{C}$ down to $25^{\circ} \mathrm{C}$. The strain induced by the differences in the in-plane lattice constants is approximately $18 \%$ and the residual stress would be $65 \mathrm{GPa}$. However, it is very unlikely that the full film is epitaxially strained to match the substrate, especially considering the 
small grain size layer at the substrate interface. The lattice mismatch is most likely accommodated by misfit dislocations and grain boundaries. Thus, it is likely that at least part of the tensile stress is intrinsically generated and that incorporated Ar atoms within the crystallites are a likely source in addition to grain growth $[41,46]$. The migration of Ar atoms to the grain boundaries would also explain the reduction in the residual tensile stresses as a result of annealing.

$\mathrm{Ar}$ and other impurity segregation might explain the increase in the crystal quality after short annealing below $1000^{\circ} \mathrm{C}$ as well. In addition, the XRD results show that the grain size increased slightly and that the orientation of the crystallites improved [47]. After annealing at $1000^{\circ} \mathrm{C}$, the crystal quality does not continue to improve and the TEM micrographs seem to indicate migration of defects to the grain boundaries. This is seen as an increase in the imaging contrast between the as-deposited and annealed film [48].

There are two sources of considerable uncertainty in determining the residual stress using the four XSA methods. In the first method, the biaxial strain was determined using the $000 l$ reflections. These reflections are affected by the out-of-plane strain, which is approximately three times smaller than the in-plane biaxial strain. Thus, the peak shift in $000 l$ reflections is small and needs to be measured with high accuracy. However, these reflections have high intensity because of the (0002) texture. In the second method, the in-plane strain was determined directly from $h k i 0$ reflections, thus the peak shift is larger and a direct result of the in-plane strain. However, the peak intensities were weak because of the grazing incidence conditions. The third method combined the in- and out-of-plane strains, with the main drawback of requiring two independent reference lattice constants. In the fourth and final method, the film was assumed to be single crystalline instead of polycrystalline, and single-crystal elastic constants were used to evaluate the strain using in- and out-ofplane strains. The diffraction elastic constants are one source of uncertainty as well. Moreover, the nanoindentation results show that $\mathrm{AlScN}$ itself becomes softer as a result of annealing, meaning that the stresses are further reduced. This was not accounted for in the $\mathrm{x}$-ray stress evaluation.

The second source of uncertainty is in the unstrained reference lattice constants themselves. Because no experimentally measured constants are available for stress-free $\mathrm{AlScN}$, the constants were estimated using DFT simulation. The lattice constants of unstrained wurtzite $\mathrm{AlScN}$ have been simulated previously $[8,12]$. However, using the previously published values gave inconsistent results, which motivated the simulation of the lattice parameters in this work. Mainly, the stress would have changed from tensile to compressive in some of the four methods as a result of annealing. The change in the AlScN lattice constants is first shown with respect to the lattice constants of pure AlN in Eq. (III A). The reason for this expression is to be able to easily correct for the systematic overestimation of lattice constants of solids characteristic of the PBE functional. In this way, the derived enhancement factors $a(x) / a_{\mathrm{AlN}}$ and $c(x) / c_{\mathrm{AlN}}$ can be used to scale the experimental lattice constants of AlN, which are more accurately known to estimate the expected lattice constants of $\mathrm{AlScN}$ at any given composition. The results show that the in-plane lattice constant $a$ grows monotonically with Sc content due to the larger atomic radius of $\mathrm{Sc}$ compared to $\mathrm{Al}$. In contrast, the lattice constant $c$ initially grows for the same reason as $a$, but eventually (beyond approximately $x=0.25$ ) starts to diminish. This is due to the preference of Sc to form a five-fold coordinated hexagonal-layered structure, in contrast to the 4-fold coordinated wurtzite structure of AIN [2].

The formation of the surface grains, which were observed only after annealing at $1000^{\circ} \mathrm{C}$, might be affected by the presence of hydrocarbons in the furnace. The FTIR results show a $\mathrm{CH}_{2}$ band at $1380 \mathrm{~cm}^{-1}$ in the films annealed at $1000^{\circ} \mathrm{C}$. The source of the hydrocarbons is likely the vacuum pump oil, which is being deposited on the films. As annealing is continued, the grains grow in size laterally and after $300 \mathrm{~h}$ of annealing, it seems like the grains have formed a continuous film. The grains seem to be mostly amorphous and according to EDS contain less $\mathrm{Al}, \mathrm{Sc}$, and $\mathrm{O}$ than the surrounding material.

The surface grains do not seem to affect the piezoelectric properties of the film, even though they are not crystalline and cannot be piezoelectric. However, because they are very thin compared to the $\mathrm{AlScN}$ film, their effect on the electric field strength and to the piezoelectric properties of the film is negligible. Even though the grains do not measurably affect the film piezoelectricity, their appearance might be a concern for surface acoustic wave (SAW) devices because rough surfaces increase the attenuation and scattering of surface acoustic waves. However, their appearance might be specific to the annealing conditions, which might not be encountered in actual use conditions.

In addition to the surface grains, a second layer seems to have formed on top of the native oxide. This layer seems to be an oxide as well and consist of Sc-rich $\mathrm{ScAlO}_{x}$. There are two likely causes why the new layer contains more $\mathrm{Sc}$ than Al. First, Sc diffuses faster in $\mathrm{AlScN}$ [49] and second, $\mathrm{Al}$ evaporates faster than Sc. The observed lattice spacing $(2.1 \AA)$ of the new layer corresponds fairly well to the spacing of (200) planes in rock-salt $\mathrm{ScO}$ [50] and $\mathrm{ScN}$ [51]. The additional bands observed in the FTIR spectra around $400-600 \mathrm{~cm}^{-1}$ are likely from this layer. The source of the oxygen atoms is the residual $\mathrm{O}_{2}$ and $\mathrm{H}_{2} \mathrm{O}$ gasses in the furnace.

The measured values for the hardness agree well with the previously published value of 13.5 GPa [48]. Even though the change in the effective hardness and Young's modulus was small, it can be considered statistically significant according to the $t$-test. The change in the hardness might be due to the decrease in the residual stress. However, residual stress should not affect the measured Young's modulus of the film [52]. Thus, the softening of the film must be a result of the changes in the film microstructure. The Young's modulus $E^{000 l}$ calculated using the DECs and Eq. (2) is approximately $189 \mathrm{GPa}$. The value measured with nanoindentation is significantly lower because of the substrate effect, which has been previously observed for AlN thin films.

\section{CONCLUSION}

This study investigated the stability of $\mathrm{AlScN}$ thin films by annealing the films under vacuum and characterizing thoroughly the effects of annealing on the film surface morphology, piezoelectric response, microstructure, mechanical 
properties, and residual stresses. Approximately 500-nmthick $\mathrm{Al}_{0.7} \mathrm{Sc}_{0.3} \mathrm{~N}$ films were deposited on $\mathrm{Si}(100)$ substrates using reactive sputtering. Films were annealed under vacuum at temperatures of $400-1000^{\circ} \mathrm{C}$ for $5 \mathrm{~h}$ while the pressure and residual gasses were monitored. Annealing at $1000^{\circ} \mathrm{C}$ was continued for up to $300 \mathrm{~h}$. The film surface was studied with SEM and AFM, and the piezoelectric response was measured using PFM. The microstructure and crystal quality were analyzed using a combination of XRD and TEM methods, EDS and FTIR. For the mechanical properties, nanoindentation was used to measure the effective Young's modulus and hardness. The residual stresses were estimated using XSA by accurately measuring the lattice constants and comparing them to unstrained reference constants, which were simulated using DFT for $x=0, \ldots, 0.5$.

Annealing increased the crystal quality of the film and maximum quality was reached at a temperature of $800^{\circ} \mathrm{C}$. Annealing at $1000^{\circ} \mathrm{C}$ caused small grains and a Sc-rich $\mathrm{AlScO}_{x}$ layer to form on the surface of the film. The grain formation was likely influenced by the presence of hydrocarbons and the Sc-rich $\mathrm{AlScO}_{x}$ was caused by the diffusion of Sc and Al through a native oxide layer and reacting with the residual oxygen in the vacuum furnace. No elemental separation, abnormal grains, or thermal decomposition were observed. Extended annealing at $1000^{\circ} \mathrm{C}$ caused $\mathrm{Ar}$ to segregate into the grain boundaries. The excess Ar reduced the biaxial stress in some of the columnar grains to an almost strain-free state, while the overall stress of the film remained tensile. Furthermore, in the region near the film-substrate interface where crystallites were small and round, the excess Ar atoms in- duced either enormous triaxial strains or more likely growth of rock-salt crystallites. The simulated lattice constants for the $\mathrm{Al}_{0.7} \mathrm{Sc}_{0.3} \mathrm{~N}$ were $a_{0}(0.3)=3.250 \AA$ and $c_{0}(0.3)=5.028 \AA$ and using them the average residual stress decreased approximately $1 \mathrm{GPa}$ as a result of annealing at $1000^{\circ} \mathrm{C}$ for $5 \mathrm{~h}$. Furthermore, the effective Young's modulus and hardness decreased slightly.

Piezoelectric AlScN thin films are very stable and can even be used in applications where high temperatures are encountered. When designing $\mathrm{AlScN}$ based piezoelectric devices, the changes in the crystal quality and mechanical properties over the lifetime of the device should be accounted for. In the future, the effect of changing crystal quality and residual stresses of AlScN thin films on device operation should be studied. A topic of future study is the effect of annealing on the piezoelectric constants of $\mathrm{AlScN}$ and the compatibility of $\mathrm{AlScN}$ with metals at high temperatures.

\section{ACKNOWLEDGMENTS}

E. Österlund appreciates the funding from the European Space Agency (NPI Grant No. 4000116390) and Aalto ELEC Doctoral School. Dr. Žukauskaite appreciates the funding from FhG Internal Programs under Grant No. Attract 005-600636. Dr. Vesa Vuorinen and Dr. Hongqun Dong are acknowledged for useful discussions. This research was conducted as a part of the EU project POSITION II (Ecsel783132-Position-II-2017-IA) and performed partly at the Aalto University OtaNano-Micronova Nanofabrication Centre and Nanomicroscopy Center.
[1] M. Akiyama, T. Kamohara, K. Kano, A. Teshigahara, Y. Takeuchi, and N. Kawahara, Enhancement of piezoelectric response in scandium aluminum nitride alloy thin films prepared by dual reactive cosputtering, Adv. Mater. 21, 593 (2009).

[2] F. Tasnádi, B. Alling, C. Höglund, G. Wingqvist, J. Birch, L. Hultman, and I. A. Abrikosov, Origin of the Anomalous Piezoelectric Response in Wurtzite $\mathrm{Sc}_{x} \mathrm{Al}_{1-x} \mathrm{~N}$ Alloys, Phys. Rev. Lett. 104, 137601 (2010).

[3] R. Matloub, M. Hadad, A. Mazzalai, N. Chidambaram, G. Moulard, C. Sandu, T. Metzger, and P. Muralt, Piezoelectric $\mathrm{Al}_{1-x} \mathrm{Sc}_{x} \mathrm{~N}$ thin films: A semiconductor compatible solution for mechanical energy harvesting and sensors, Appl. Phys. Lett. 102, 152903 (2013).

[4] K. R. Talley, S. L. Millican, J. Mangum, S. Siol, C. B. Musgrave, B. Gorman, A. M. Holder, A. Zakutayev, and G. L. Brennecka, Implications of heterostructural alloying for enhanced piezoelectric performance of $(\mathrm{Al}, \mathrm{Sc}) \mathrm{N}$, Phys. Rev. Mater. 2, 063802 (2018).

[5] M. Akiyama, K. Umeda, A. Honda, and T. Nagase, Influence of scandium concentration on power generation figure of merit of scandium aluminum nitride thin films, Appl. Phys. Lett. 102, 021915 (2013).

[6] Q. Wang, Y. Lu, S. Fung, X. Jiang, S. Mishin, Y. Oshmyansky, and D. A. Horsley, Scandium doped aluminum nitride based piezoelectric micromachined ultrasound transducers, in Proceedings of Solid-State Sensors, Actuators, and Microsystems Workshop (Transducer Research Foundation, San Diego. CA, 2016), p. 436.

[7] M. Moreira, J. Bjurström, I. Katardjev, and V. Yantchev, Aluminum scandium nitride thin-film bulk acoustic resonators for wide band applications, Vacuum 86, 23 (2011).

[8] S. Zhang, D. Holec, W. Y. Fu, C. J. Humphreys, and M. A. Moram, Tunable optoelectronic and ferroelectric properties in Sc-based III-nitrides, J. Appl. Phys. 114, 133510 (2013).

[9] M. Akiyama, K. Kano, and A. Teshigahara, Influence of growth temperature and scandium concentration on piezoelectric response of scandium aluminum nitride alloy thin films, Appl. Phys. Lett. 95, 162107 (2009).

[10] S. Fichtner, N. Wolff, G. Krishnamurthy, A. Petraru, S. Bohse, F. Lofink, S. Chemnitz, H. Kohlstedt, L. Kienle, and B. Wagner, Identifying and overcoming the interface originating c-axis instability in highly Sc enhanced AlN for piezoelectric micro-electromechanical systems, J. Appl. Phys. 122, 035301 (2017).

[11] P. Mayrhofer, A. Bittner, and U. Schmid, High temperature stability of $\mathrm{Sc}_{x} \mathrm{Al}_{1-x} \mathrm{~N}(\mathrm{x}=0.27)$ thin films, in Smart Sensors, Actuators, and MEMS VII; and Cyber Physical Systems (SPIE, Bellingham, WA, 2015), Vol. 9517, p. 95171C. 
[12] C. Höglund, J. Birch, B. Alling, J. Bareño, Z. Czigány, P. O. Persson, G. Wingqvist, A. Zukauskaite, and L. Hultman, Wurtzite structure $\mathrm{Sc}_{1-x} \mathrm{Al}_{x} \mathrm{~N}$ solid solution films grown by reactive magnetron sputter epitaxy: Structural characterization and first-principles calculations, J. Appl. Phys. 107, 123515 (2010).

[13] Y. Lu, M. Reusch, N. Kurz, A. Ding, T. Christoph, M. Prescher, L. Kirste, O. Ambacher, and A. Žukauskaite, Elastic modulus and coefficient of thermal expansion of piezoelectric $\mathrm{Al}_{1-x} \mathrm{Sc}_{x} \mathrm{~N}$ (up to $\mathrm{x}=0.41$ ) thin films, APL Mater. 6, 076105 (2018).

[14] S. Fichtner, T. Reimer, S. Chemnitz, F. Lofink, and B. Wagner, Stress controlled pulsed direct current co-sputtered $\mathrm{Al}_{1-x} \mathrm{Sc}_{x} \mathrm{~N}$ as piezoelectric phase for micromechanical sensor applications, APL Mater. 3, 116102 (2015).

[15] C. Höglund, J. Bareño, J. Birch, B. Alling, Z. Czigány, and L. Hultman, Cubic $\mathrm{Sc}_{1-x} \mathrm{Al}_{x} \mathrm{~N}$ solid solution thin films deposited by reactive magnetron sputter epitaxy onto $\mathrm{ScN}$ (111), J. Appl. Phys. 105, 113517 (2009).

[16] A. Žukauskaite, C. Tholander, F. Tasnádi, B. Alling, J. Palisaitis, J. Lu, P. O. Persson, L. Hultman, and J. Birch, Stabilization of wurtzite $\mathrm{Sc}_{0.4} \mathrm{Al}_{0.6} \mathrm{~N}$ in pseudomorphic epitaxial $\mathrm{Sc}_{x} \mathrm{Al}_{1-x} \mathrm{~N} / \mathrm{In}_{y} \mathrm{Al}_{1-y} \mathrm{~N}$ superlattices, Acta Mater. 94, 101 (2015).

[17] A. Zukauskaite, G. Wingqvist, J. Palisaitis, J. Jensen, P. O. Persson, R. Matloub, P. Muralt, Y. Kim, J. Birch, and L. Hultman, Microstructure and dielectric properties of piezoelectric magnetron sputtered $\mathrm{w}-\mathrm{Sc}_{x} \mathrm{Al}_{1-x} \mathrm{~N}$ thin films, J. Appl. Phys. 111, 093527 (2012).

[18] C. B. Karuthedath, A. T. Sebastian, J. Saarilahti, T. Sillanpaa, and T. Pensala, Design and Fabrication of Aluminum Nitride Piezoelectric Micromachined Ultrasonic Transducers for Air Flow Measurements, in 2019 IEEE International Ultrasonics Symposium (IUS) (IEEE, New York, 2019), pp. 2489-2492.

[19] P. Daoust, P. Desjardins, R. A. Masut, V. Gosselin, and M. Côté, Ab initio piezoelectric properties of $\mathrm{Al}_{0.5} \mathrm{Sc}_{0.5} \mathrm{~N}$ : Impact of alloy configuration on the $\mathrm{d}_{33, f}$ piezoelectric strain coefficient, Phys. Rev. Mater. 1, 055402 (2017).

[20] M. A. Caro, S. Zhang, T. Riekkinen, M. Ylilammi, M. A. Moram, O. Lopez-Acevedo, J. Molarius, and T. Laurila, Piezoelectric coefficients and spontaneous polarization of ScAlN, J. Phys.: Condens. Matter 27, 245901 (2015).

[21] M. David Henry, T. R. Young, and B. Griffin, ScAlN etch mask for highly selective silicon etching, J. Vac. Sci. Technol. B 35, 052001 (2017).

[22] M. T. Hardy, B. P. Downey, D. J. Meyer, N. Nepal, D. F. Storm, and D. S. Katzer, Epitaxial ScAlN etch-stop layers grown by molecular beam epitaxy for selective etching of AlN and GaN, IEEE Trans. Semicond. Manuf. 30, 475 (2017).

[23] S. Zhang, W. Fu, D. Holec, C. Humphreys, and M. Moram, Elastic constants and critical thicknesses of ScGaN and ScAlN, J. Appl. Phys. 114, 243516 (2013).

[24] J. D. Eshelby, The determination of the elastic field of an ellipsoidal inclusion, and related problems, Proc. R. Soc. London, Ser. A: Math. Phys. Sci. 241, 376 (1957).

[25] E. Kröner, Berechnung der elastischen Konstanten des Vielkristalls aus den Konstanten des Einkristalls, Z. Phys. 151, 504 (1958).
[26] G. Kresse and J. Furthmüller, Efficient iterative schemes for ab initio total-energy calculations using a plane-wave basis set, Phys. Rev. B 54, 11169 (1996).

[27] G. Kresse and D. Joubert, From ultrasoft pseudopotentials to the projector augmented-wave method, Phys. Rev. B 59, 1758 (1999).

[28] J. P. Perdew, K. Burke, and M. Ernzerhof, Generalized Gradient Approximation Made Simple, Phys. Rev. Lett. 77, 3865 (1996).

[29] M. Moakher and A. N. Norris, The closest elastic tensor of arbitrary symmetry to an elasticity tensor of lower symmetry, J. Elast. 85, 215 (2006).

[30] M. A. Caro, Extended scheme for the projection of material tensors of arbitrary symmetry onto a higher symmetry tensor, arXiv:1408.1219.

[31] A. Sanz-Hervás, E. Iborra, M. Clement, J. Sangrador, and M. Aguilar, Influence of crystal properties on the absorption IR spectra of polycrystalline AIN thin films, Diamond Relat. Mater. 12, 1186 (2003).

[32] L. Vergara, J. Olivares, E. Iborra, M. Clement, A. Sanz-Hervás, and J. Sangrador, Effect of rapid thermal annealing on the crystal quality and the piezoelectric response of polycrystalline AlN films, Thin Solid Films 515, 1814 (2006).

[33] P. Mayrhofer, C. Eisenmenger-Sittner, H. Euchner, A. Bittner, and U. Schmid, Influence of c-axis orientation and scandium concentration on infrared active modes of magnetron sputtered $\mathrm{Sc}_{x} \mathrm{Al}_{1-x} \mathrm{~N}$ thin films, Appl. Phys. Lett. 103, 251903 (2013).

[34] W. C. Oliver and G. M. Pharr, An improved technique for determining hardness and elastic modulus using load and displacement sensing indentation experiments, J. Mater. Res. 7, 1564 (1992).

[35] D. Nilsson, E. Janzén, and A. Kakanakova-Georgieva, Lattice parameters of AlN bulk, homoepitaxial and heteroepitaxial material, J. Phys. D: Appl. Phys. 49, 175108 (2016).

[36] P. Zaumseil, High-resolution characterization of the forbidden Si 200 and Si 222 reflections, J. Appl. Crystallogr. 48, 528 (2015).

[37] A. Collins, E. Lightowlers, and P. Dean, Lattice vibration spectra of aluminum nitride, Phys. Rev. 158, 833 (1967).

[38] P. Feijoo, M. Pampillón, E. San Andrés, and M. Lucía, Optimization of scandium oxide growth by high pressure sputtering on silicon, Thin Solid Films 526, 81 (2012).

[39] G. W. Snedecor and W. G. Cochran, Statistical Methods, 7th ed., (Iowa State University Press, Ames, IA, 1980).

[40] I. Yonenaga, T. Shima, and M. H. Sluiter, Nano-indentation hardness and elastic moduli of bulk single-crystal AlN, Jpn. J. Appl. Phys. 41, 4620 (2002).

[41] R. Koch, The intrinsic stress of polycrystalline and epitaxial thin metal films, J. Phys.: Condens. Matter 6, 9519 (1994).

[42] A. R. Denton and N. W. Ashcroft, Vegard's law, Phys. Rev. A 43, 3161 (1991).

[43] H. Vollstädt, E. Ito, M. Akaishi, S.-I. Akimoto, and O. Fukunaga, High pressure synthesis of rocksalt type of AlN, Proc. Jpn. Acad., Ser. B 66, 7 (1990).

[44] J. Schuster and J. Bauer, The ternary systems Sc-Al-N and YAl-N, J. Less-Common Met. 109, 345 (1985).

[45] W. Yim and R. Paff, Thermal expansion of AlN, sapphire, and silicon, J. Appl. Phys. 45, 1456 (1974). 
[46] M. F. Doerner and W. D. Nix, Stresses and deformation processes in thin films on substrates, Crit. Rev. Solid State Mater. Sci. 14, 225 (1988).

[47] M. Moram and M. Vickers, X-ray diffraction of III-nitrides, Rep. Prog. Phys. 72, 036502 (2009).

[48] O. Zywitzki, T. Modes, S. Barth, H. Bartzsch, and P. Frach, Effect of scandium content on structure and piezoelectric properties of $\mathrm{AlScN}$ films deposited by reactive pulse magnetron sputtering, Surf. Coat. Technol. 309, 417 (2017).

[49] J. L. Schroeder, B. Saha, M. Garbrecht, N. Schell, T. D. Sands, and J. Birch, Thermal stability of epitaxial cubic-TiN/(Al,Sc)N metal/semiconductor superlattices, J. Mater. Sci. 50, 3200 (2015).

[50] V. Dufek, F. Petru, and V. Brozek, Über sauerstoff-haltige verbindungen vom strukturtyp B1 der ersten vier übergangsmetalle, Monatsh. Chem. Verw. Teile Anderer Wiss. 98, 2424 (1967).

[51] W. Lengauer, Investigations in the scandium-nitrogen system, J. Solid State Chem. 76, 412 (1988).

[52] Z.-H. Xu and X. Li, Influence of equi-biaxial residual stress on unloading behaviour of nanoindentation, Acta Mater. 53, 1913 (2005). 